\title{
Isolamento de Streptococcus spp de tilápias do nilo (Oreochromis niloticus) e qualidade da água de tanques rede na Região Norte do Estado do Paraná, Brasil
}

\section{Isolation of Streptococcus spp from nile tilapia (Oreochromis niloticus) and quality of water in hapas nets in North Region of Parana State, Brazil}

\author{
Rogério Salvador ${ }^{1}$; Ernst Eckehardt Müller ${ }^{2 *}$; Júlio Hermann Leonhardt ${ }^{3}$; \\ Luciene Garcia Pretto-Giordano²; Juliana Alves Dias ${ }^{4}$; Júlio César de Freitas²; \\ Aleksey Machado Moreno ${ }^{5}$
}

\begin{abstract}
Resumo
Foram estudados doze tanques-rede de quatro propriedades de criação intensiva de tilápia do Nilo (Oreochomis niloticus) da região Norte do Paraná, Brasil. No período de 13 meses foram analisados 71 peixes provenientes de tanques apresentando morbidade e mortalidade de tilápias. Paralelamente, para avaliar a qualidade da água destes tanques, foi medida a temperatura, oxigênio dissolvido, $\mathrm{pH}$, alcalinidade, nitrito e amônia. Dos 71 peixes, foram coletadas 220 materiais biológicos. Em 17 (23.94\%) peixes foram isolados Streptococcus spp e dos 53 materiais biológicos provenientes destes peixes, 24 (45.28\%) apresentaram Streptococcus spp. Os principais sinais clínicos e lesões macroscópicas nos peixes com isolamento de Streptococcus spp foram hepatomegalia e esplenomegalia, lesão de pele e base das nadadeiras e exoftalmia com opacidade de córnea. O maior número de infecções estreptocócicas ocorreu nos meses com temperaturas mais elevadas, principalmente no período de transição inverno para primavera. Os valores de oxigênio dissolvido, $\mathrm{pH}$, alcalinidade, nitrito e amônia da água estiveram dentro da normalidade.
\end{abstract}

Palavras-chave: Peixe, Streptococcus spp, tanque-rede, sinais clínicos, qualidade da água.

\begin{abstract}
This study evaluated 12 intensive breed of Nile tilapia (Oreochromis niloticus) in four properties localized in the north of Parana State, Brazil. In the period of 13 months, 71 fishes were collected and analyzed of hapas nets that presenting morbidity and mortality of tilapias. Parallel, to evaluate the quality of the water of these hapas nets, there was measured the temperature, dissolved oxygen, $\mathrm{pH}$, alkalinity, nitrite and ammonia. Of the 71 fishes, were collected 220 biological samples. 17 (23.94\%) fishes were positive for Streptococcus spp. Of the 53 biological samples from 17 fishes, in 24 (45.28\%) were isolated streptococci.
\end{abstract}

\footnotetext{
Fundação Faculdade Luiz Meneguel (FFMAL), Bandeirantes, Pr

${ }^{2}$ Laboratório de Bacteriologia, Departamento de Medicina Veterinária Preventiva (DMVP),Centro de Ciências Agrárias (CCA), Universidade Estadual de Londrina (UEL). Caixa Postal: 6001, CEP: 86051-990, Londrina, Paraná, Brasil. E-mail: muller@ uel.br

${ }^{3}$ Laboratório de Fisiologia, Departamento de Fisiologia, Centro de Ciências Biológicas, UEL.

${ }^{4}$ Aluna do Programa de Pós-graduação em Ciência Animal (área de concentração: Sanidade Animal; nível: Mestrado) UEL.

5 Aluno do Curso de Graduação em Medicina Veterinária

* Autor para correspondência.
} 
Salvador, R. et al.

The main clinical signs and macroscopic lesions in the fishes with isolation of Streptococcus spp. were hepatomegaly and splenomegaly, skin lesion and base of the fins and exoftalmia with cornea opacity. The higher incidence of infections caused by streptococci happened in the months with higher temperatures, mainly in the transition period winter for spring. The values of dissolved oxygen, $\mathrm{pH}$, alkalinity, nitrite and ammonia of the water were normal.

Key words: Fish, Streptococcus spp, clinical signs, quality of water.

\section{Introdução}

A piscicultura brasileira passa por uma fase de expansão e consolidação (CHAMMAS, 1997). A produção anual de tilápia do Nilo (Oreochromis niloticus) no Brasilé de 30 a 40 mil toneladas. Estimase que a captura em reservatórios iguale a produção em cultivo e, assim, estes números somados seguramente colocam o Brasil como um dos principais produtores na América Latina (KUBITZA, 2000).

O sistema de cultivo intensivo, usualmente praticado pelas pisciculturas industriais, caracterizase pelas altas densidades de estocagem e elevado nível de arraçoamento (SHOEMAKER; EVANS; KLESIUS, 2000). Nesse tipo de exploração comercial, surgem com frequiência problemas de manejo inadequado, nutricionais, enfermidades infecciosas e parasitárias (THATCHER; BRITES NETO, 1994; MARTINS; ROMERO, 1996; MARTINS, 1998).

O maior problema sanitário de origem bacteriana em sistemas de cultivo intensivo de tilápias (Oreochromis spp) é a septicemia causada por Streptococcus spp ou Enterococcus spp (SURESH, 1998). A criação de peixes susceptíveis à infecção estreptocócica em sistemas intensivos tem levado a grandes perdas por esta doença (PERERA; JOHNSON, 1994; ELDAR et al., 1997). Dentre as diferentes espécies de estreptococos responsáveis por infecções em peixes, destaca-se o Streptococcus iniae, descrito pela primeira vez em 1976, por Píer e Madin. Atualmente, esta espécie é considerada pela Associação Americana de Tilápias (AMERICAN TILAPIA ASSOCIATION, 1998) como o mais importante patógeno para essa espécie de peixe. Outros estreptococos patógenos de peixes citados na literatura são: Streptococcus faecium (KUSUDA et al., 1976;
MINAMI, 1979); Streptococcus agalactiae (KUSUDA; KOMATSU, 1978), Streptococcus equi, Streptococcus equisimilis, Streptococcus pyogenes, Streptococcus zooepidemicus (UGAJIN, 1981) e Streptococcus difficile (ELDAR; BEJERANO; BERCOVIER, 1994).

Os sinais clínicos observados em peixes infectados por Streptococcus spp são típicos de septicemia (PLUMB, 1999) e são atribuídos às exotoxinas que podem ser altamente tóxicas a baixas concentrações (RASHEED; PLUMB, 1984). A patogenicidade do Streptococcus spp está associada às condições de estresse relacionado à qualidade da água e condições de criação intensiva (BUNCH; BEJERANO, 1997). As características físicas e químicas da água estão intimamente relacionadas entre si, sendo que, a mudança de um parâmetro interfere com o outro, podendo acarretar problemas na produção primária (fitoplâncton), secundária (zooplâncton) e finalmente nos peixes (CASTAGNOLLI, 1992). Baixas concentrações de oxigênio dissolvido, níveis tóxicos de amônia e nitrito, mudanças bruscas de temperatura e pH são algumas das características da água responsáveis pela ocorrência de mortalidade durante o cultivo (ALABASTER; LLOYD, 1982; PÁDUA, 1993; FERNANDES; RANTIN, 1994).

O objetivo do trabalho foi identificar as principais alterações clínicas e lesões macroscópicas em tilápia do Nilo infectadas por Streptococcus spp e avaliar a qualidade da água em sistemas de cultivo intensivo.

\section{Material e Métodos}

Foram estudados doze tanques-rede de quatro propriedades de criação intensiva de tilápia do Nilo, 
da região Norte do Paraná, Brasil, no período de abril de 2001 a abril de 2002. Os peixes apresentavam peso médio de 500 gramas e eram estocados com biomassa que variava de 100 a $250 \mathrm{Kg} / \mathrm{m}^{3}$. As coletas foram realizadas quando da ocorrência de morbidade e mortalidade nos tanques. Peixes apresentando sinais de escurecimento de pele, letargia, natação errática e circular foram capturados e acondicionados em sacos plásticos contendo água do próprio local, oxigênio sob pressão, transportados até o Laboratório de Bacteriologia do Departamento de Medicina Veterinária Preventiva da Universidade Estadual de Londrina - UEL e examinados imediatamente.

Concomitantemente às coletas dos peixes, foram avaliadas a temperatura da água e a concentração de oxigênio dissolvido em oxímetro YSI, modelo 550 Yellow Spring, USA. O pH das amostras foi obtido diretamente, com auxílio de um peagâmetro digital de campo PS 15. A alcalinidade total foi determinada por titulação potenciométrica, usando-se como titulante ácido sulfúrico $0,02 \mathrm{~N}$, como recomendado por Golterman, Clymo e Ohnstad (1978) e expressa em mg/L, segundo Tavares (1995a). As concentrações do nitrito foram determinadas segundo a metodologia descrita por Golterman, Clymo e Ohnstad (1978) e os resultados expressos em mg/L. Os valores de amônia foram obtidos por análise de titulação, através de Kit comercial colorimétrico (Kit, Laboratório Alfa Tecnoquímica, Brasil).

No laboratório, os peixes foram submetidos ao exame físico externo e à necropsia, sendo anotadas as alterações macroscópicas. Foram coletadas assepticamente amostras de rim, encéfalo e fígado de todos os animais, além de raspado de pele, líquido abdominal e olho, que apresentavam alterações macroscópicas. Para os exames bacteriológicos foram coletados 71 peixes e utilizadas 220 amostras de material biológico, sendo 71 de encéfalo, 71 de fígado, 71 de rim, quatro de pele, dois de líquido abdominal e uma amostra de olho.

Inicialmente, o material foi semeado em ágar BHI (Brain Heart Infusion - Difco), suplementado com
$1 \%$ de extrato de levedura e $5 \%$ de sangue ovino desfibrinado, sendo incubadas a $29^{\circ} \mathrm{C}$ em atmosfera de aerofilia durante cinco dias. Após o período de incubação, a identificação dos microrganismos foi efetuada segundo as características culturais, morfológicas, tintoriais e bioquímicas (KRIEG; HOLT, 1984). Os estreptococos previamente caracterizados pela prova da catalase, prova de crescimento em azul de metileno, $\mathrm{NaCl}$ a $6,5 \%$, bile $40 \%$ e esculina, foram classificados em grupos pelo SLIDEX STREPTOKIT (BioMerieux, França).

\section{Resultados e Discussão}

Os principais sinais clínicos observados nos 71 peixes coletados foram natação errática e circular, escurecimento de pele e letargia. Esses sinais clínicos são compatíveis a infecção estreptocócica.

Dos 71 peixes pesquisados, 17 (23,94\%), apresentaram crescimento de Streptococcus spp, em $24(45,28 \%)$ das 53 amostras estudadas (Tabela 1).

Tabela 1. Origem dos isolamentos de Streptococcus spp. de 17 tilápias do Nilo (Oreochromis niloticus) e 53 materiais biológicos.

\begin{tabular}{llll}
\hline \multirow{2}{*}{ Material biológico } & \multicolumn{3}{l}{ Streptococcus spp } \\
\cline { 2 - 4 } & Total & Isolamentos & $\mathbf{\%}$ \\
\hline Encéfalo & 17 & 12 & 70,6 \\
Fígado & 17 & 5 & 29,4 \\
Rim & 17 & 5 & 29,4 \\
Líquido abdominal & 2 & 2 & 100,0 \\
Total & $\mathbf{5 3}$ & $\mathbf{2 4}$ & \\
\hline
\end{tabular}

Verificou-se a predominância de Streptococcus spp. em 12 das 17 amostras de encéfalo analisadas. No ágar BHI as colônias de estreptococos apresentaram-se de coloração cinza, translúcidas, circulares, ligeiramente convexas, puntiformes e não hemolíticas. Todas cepas apresentaram resultado negativo nas provas da catalase, crescimento em 
$\mathrm{NaCl}$ a $6,5 \%$, bile $40 \%$, esculina e azul de metileno. As 24 culturas de estreptococos submetidas à prova de látex-aglutinação apresentaram o antígeno carboidrato pertencente ao grupo B de Lancefield. $\mathrm{Na}$ literatura predominam os relatos de isolamentos de $S$. iniae em tilápias do Nilo (PERERA; JOHNSON, 1994; ELDAR et al., 1995; BOWSER; WOOSTER; GETCHELL, 1998; EVANS; SHOEMAKER; KLESIUS, 2000). Em países ou regiões de clima quente são relatados isolamentos de estreptococos não hemolíticos no ágar sangue e do grupo B de Lancefield (COOK; LOFTON, 1975; BUNCH; BEJERANO, 1997). Eldar, Bejerano e Bercovier (1994) e Vandamme et al. (1997) relataram a ocorrência de $S$. difficile, um estreptococo não hemolítico do grupo B, causando meningoencefalite em tilápia do Nilo com elevadas perdas econômicas.

As lesões observadas em pele e na base das nadadeiras, variaram de pequenas áreas de descamação a extensas áreas inflamatória e ulcerativa. Foram observadas palidez das brânquias com necrose das extremidades. Presença de líquido abdominal do tipo exsudato.

Na Tabela 2 encontram-se as principais alterações macroscópicas observadas nos 71 peixes necropsiados. Nesta Tabela, verifica-se a predominância da hepatomegalia com palidez do órgão, esplenomegalia, lesão de pele e em base das nadadeiras, salientando-se que nas tilápias com isolamento de Streptococcus spp, a predominância destes achados foi mais elevada.
Tabela 2. Principais alterações macroscópicas observadas nas 71 tilápia do Nilo (Oreochromis niloticus) submetidas ao exame bacteriológico e nas 17 positivas para Streptococcus spp.

\begin{tabular}{|c|c|c|c|c|}
\hline \multirow[t]{2}{*}{ Tipos de lesões } & \multicolumn{2}{|c|}{$\begin{array}{l}\text { Total de peixes } \\
\text { analisados }\end{array}$} & \multicolumn{2}{|c|}{$\begin{array}{c}\text { Total de peixes } \\
\text { positivos para } \\
\text { Streptococcus spp. }\end{array}$} \\
\hline & $\mathbf{N}^{\mathbf{0}}$ & $\%$ & $\mathrm{~N}^{0}$ & $\%$ \\
\hline Lesão de pele & 16 & 22,53 & 6 & 35,29 \\
\hline $\begin{array}{l}\text { Lesão em base } \\
\text { das nadadeiras }\end{array}$ & 16 & 22,53 & 6 & 35,29 \\
\hline $\begin{array}{l}\text { Exoftalmia e opacidade } \\
\text { de córnea }\end{array}$ & 8 & 11,26 & 5 & 29,41 \\
\hline Lesão em brânquias & 9 & 12,67 & 4 & 23,52 \\
\hline $\begin{array}{l}\text { Líquido em cavi- } \\
\text { dade abdominal }\end{array}$ & 2 & 2,81 & 2 & 11,76 \\
\hline $\begin{array}{l}\text { Hepatomegalia e } \\
\text { palidez do órgão }\end{array}$ & 17 & 23,94 & 12 & 70,58 \\
\hline Esplenomegalia & 17 & 23,94 & 10 & 58,82 \\
\hline
\end{tabular}

Na Figura 1 são observados o número de tanquesrede com morbidade e mortalidade de tilápia do Nilo (Oreochromis niloticus), número de tanques rede com isolamento de Streptococcus spp, valores de oxigênio dissolvido e temperatura da água durante $o$ período de coleta.

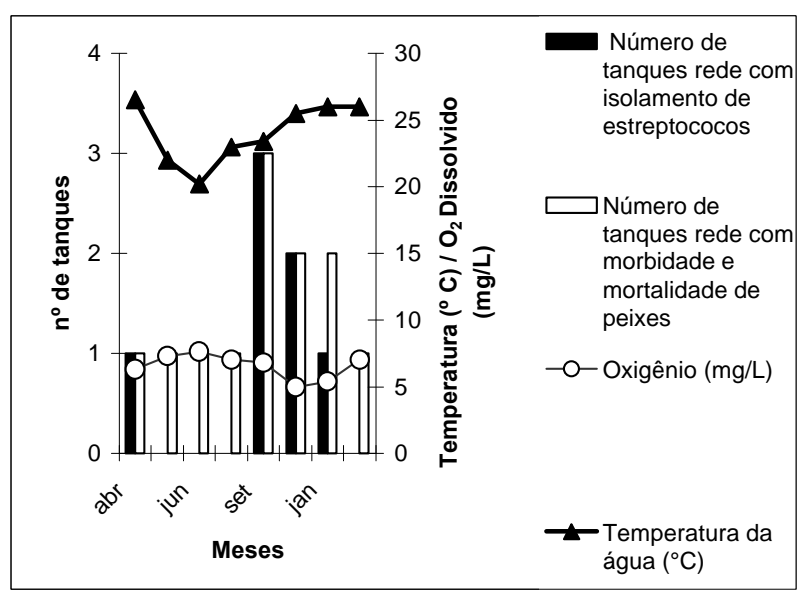

Figura 1. Morbidade e mortalidade de tilápias em 12 tanques rede, isolamento de Streptococcus spp, valores médios de oxigênio dissolvido e temperatura da água. 
Observa-se que, o maior número de coletas de peixes com sinais clínicos e isolamento de Streptococcus spp. ocorreram entre os meses de setembro de 2001 e janeiro de 2002. A partir de junho ocorreu a elevação gradativa da temperatura da água onde estavam instalados os tanques rede, tendo sido observada a temperatura mais elevada no mês de janeiro $\left(26,5^{\circ} \mathrm{C}\right)$. O número de isolamentos de Streptococcus spp aumentou bruscamente no mês de setembro, período de transição entre inverno e primavera, decrescendo nos meses subseqüentes apesar das temperaturas manterem-se elevadas. Os períodos de risco ocorreram nas estações do ano em que houve mudanças acentuadas na temperatura, situação esta que pode levar a estresse e imunossupressão dos peixes (VAN MUISWINKEL, 1985). Vários pesquisadores relacionam temperaturas mais elevadas com maior ocorrência de infecções por estreptococos em peixes (ROBERTS; SOMERVILLE, 1982; KITAO, 1993). Segundo Chang e Plumb (1996), as tilápia do Nilo foram mais susceptíveis a infecção por estreptococos a temperaturas compreendidas entre 25 e $30^{\circ} \mathrm{C}$. Ortega et al. (1995) afirmam existir relação direta entre surtos de infecções bacterianas com a temperatura e indireta a associação entre doença e estação do ano.

As concentrações de oxigênio dissolvido da água dos tanques apresentaram valores entre $4,0 \mathrm{mg} / \mathrm{L} \mathrm{e}$ 7,6 mg/L. A maior concentração do oxigênio dissolvido ocorreu em junho e a menor em novembro, observando-se uma relação inversa entre a temperatura e o oxigênio dissolvido. A quantidade ideal de oxigênio dissolvido em sistemas de cultivo intensivo está compreendida entre 4,0 e 6,0 mg/L (CASTAGNOLLI, 1992). Ainda que os valores encontrados estivessem dentro da faixa recomendada, a maior frequiência de isolamentos foi observada nos períodos de menor concentração de oxigênio dissolvido. Bunch e Bejerano (1997), verificaram que baixos níveis de oxigênio dissolvido elevaram a mortalidade em tilápias híbridas (Oreochromis niloticus x Oreochromis aureus) experimentalmente infectadas. Bowser, Wooster e
Getchell (1998), observaram que baixos níveis de oxigênio dissolvido associado a temperaturas mais altas representam um fator estressante para tilápia do Nilo podendo levar a maiores taxas de infecção por estreptococos.

Os valores do $\mathrm{pH}$ e alcalinidade total detectados ao longo do experimento constam da Tabela 3.

Tabela 3. Valores médios de alcalinidade e $\mathrm{pH}$ da água em 12 tanques rede com morbidade e mortalidade de tilápias do Nilo (Oreochromis niloticus), com isolamento de Streptococcus spp.

\begin{tabular}{ccc}
\hline Meses & PH & Alcalinidade \\
\hline abril & 6,5 & 28 \\
maio & 7 & 24 \\
junho & 6,5 & 24 \\
agosto & 6,6 & 25 \\
setembro & 7,1 & 44 \\
novembro & 7,2 & 31 \\
janeiro & 7,4 & 27 \\
abril & 6,5 & 30 \\
\hline
\end{tabular}

$\mathrm{O} \mathrm{pH}$ variou de 6,5 a 7,4, e esteve dentro dos valores ideais de $\mathrm{pH}$ recomendado à piscicultura (ALABASTER; LLOYD, 1982; BOYD, 1990; TAVARES, 1995a). Segundo Perera, Johnson e Donald (1997), águas alcalinas com pH maior que oito, propiciam condições ideais para a ocorrência de infecções estreptocócicas por potencializarem a toxidez da amônia.

Os valores da alcalinidade total variaram de 22 a $60 \mathrm{mg} \mathrm{CaCO} / \mathrm{L}$. A alcalinidade funciona como um tampão regulador do $\mathrm{pH}$ da água do tanque ou viveiro. Em águas com alcalinidade acima de 20,0 mg/L ocorre melhor desenvolvimento do fitoplâncton e mudanças diárias bruscas do $\mathrm{pH}$ são minimizadas (TAVARES; MORENO, 1994; TAVARES, 1995b; POPMA; LOVSHIN, 1995).

Dos doze tanques-rede estudados, somente um apresentou valor de amônia de $0,5 \mathrm{mg} / \mathrm{L}$. Nos três 
peixes deste tanque-rede, submetidos ao exame bacteriológico, foi isolado Streptococcus spp. Segundo Alabaster e Lloyd (1982), valores de amônia superiores a $0,025 \mathrm{mg} / \mathrm{L}$ são inadequados ao desenvolvimento dos peixes. A amônia é um metabólito proveniente da excreção nitrogenada dos peixes e outros organismos aquáticos e da decomposição microbiana de resíduos orgânicos. Sua presença pode prejudicar o desempenho do peixe, aumentar a incidência de doenças e até mesmo, causar a morte direta por intoxicação (KUBITZA, 2000).

Os valores de nitrito em todos os tanques-rede analisados foram nulos. $\mathrm{O}$ nitrito é um componente intermediário do processo de nitrificação e pode ser proveniente da oxidação da amônia ou, mais raramente, da redução do nitrato. A concentração de nitrito pode chegar a níveis tóxicos e conseqüentemente se tornar um fator limitante no desempenho da produção na aqüicultura (BOYD, 1990). O valor máximo de concentração de nitrito aceitável num cultivo é de 1.0mg/L (PÁDUA, 1993).

A biomassa de peixes pode influenciar a morbidade e mortalidade de peixes por estreptococos e outras bactérias. No presente trabalho, todos os tanques-rede apresentaram biomassas variando de 100 a $250 \mathrm{~kg} / \mathrm{m}^{3}$. Shoemaker, Evans e Klesius (2000), em experimento realizado em aquários, observaram que, com o aumento da densidade de estocagem, elevaram-se as taxas de mortalidade de tilápia do Nilo por Streptococcus iniae, devido provavelmente, à carga bacteriana mais elevada e maior contato direto entre os peixes. Clark, Paller e Smith (2000), verificaram que o aumento da densidade populacional é diretamente proporcional à ocorrência de abrasões de pele nos peixes, indicando que esta é uma das principais vias de infecção. Além disso, a ingestão de olhos e vísceras de peixes mortos por peixes saudáveis, também se constituí em porta de entrada para os estreptococos.

Segundo Bunch e Bejerano (1997), os estreptococos são bactérias oportunistas amplamente distribuídas no ambiente aquático e sua patogenicidade está associada às condições de estresse relacionadas à qualidade da água e condições de criação intensiva. Dessa forma, o estresse gerado pelo sistema de cultivo intensivo em tanques rede aos quais os peixes estudados foram submetidos, associados às alterações na qualidade da água, principalmente no que se refere à temperatura $\mathrm{e}$ níveis de oxigênio dissolvido, provavelmente foram os elementos responsáveis pelo aumento da suscetibilidade dos peixes à infecção por Streptococcus spp.

\section{Referências}

ALABASTER, J. S.; LLOYD, R. Water quality for freshwater fish. $2^{\text {th }}$ ed. London: Butterworth Scientific, 1982.

\section{AMERICAN TILAPIA ASSOCIATION. Tilapia situation} and outlook report: Califórnia, 1998.

BOYD, C. E. Water quality in ponds for aquaculture. Alabama: Alabama Agricultural Experiment Station, 1990.

BOWSER, P. R.; WOOSTER, G. A.; GETCHELL, R. G. Streptococcus iniae infection of Oreochromis niloticus in a recirculation production facility. Journal of the World Aquaculture Society, Baton Rouge, v.29, n.3, p.335-339, 1998.

BUNCH, E. C.; BEJERANO, I. The effect of environmental factors on the susceptibility of hibrid tilapia Oreochromis niloticus x Oreochromis aureus to streptococcosis. Israeli Journal Aquaculture, Bamidgeh, v.49, n.2, p.67-76, 1997.

CASTAGNOLLI, N. Criação de peixes de água doce. Jaboticabal: FUNEP, 1992.

CHAMMAS, M. Panorama da aqüicultura brasileira: a região Sul. In: WORKSHOP INTERNACIONAL DE AQUICULTURA, 1997, São Paulo. Anais... São Paulo, 1997. p.56-61.

CHANG, P. H.; PLUMB, J. A. Effects of salinity on Streptococcus infection of Nile tilapia, Oreochromis niloticus. Journal of Applied Aquaculture, Binghamton, v.6, p. 39-45, 1996.

CLARK, J. S.; PALLER, B.; SMITH, P. D. Prevention of streptococcosis in tilapia by vaccination: the Philippine experience. In: INTERNATIONAL SYMPOSIUM ON TILAPIA AQUACULTURE, 5., 2000, Rio de Janeiro. Proceedings... Rio de Janeiro, 2000. v.2, p.545-551.

COOK, D. W.; LOFTON, S. R. Pathogenicity studies with a Streptococcus sp. isolated from fishes in AlabamaFlorida fish kill. Transactions of the American Fisheries Society, Bethesda, v.2, p. 286-288, 1975. 
ELDAR, A.; BEJERANO, Y.; BERCOVIER, H. Streptococcus shiloi and Streptococcus diffcile: two new streptococcal species causing a meningoencephalitis in fish. Current Microbiology, New York, v.28, p.139-143, 1994.

ELDAR, A.; FRELIER, P. F.; ASSENTA, L.; VARNER, P. W.; LAWHON, S.; BERCOVIER, H. Streptococcus shiloi, the name for an agent causing septicemic infection in fish, is a junior synonym of Streptococcus iniae. International Journal of Systematics Bacteriology, Reading, v.45, p.840$842,1995$.

ELDAR, A.; LAWHON, S.; FRELIER, P.; ASSENTA, L.; SIMPSON, B.; VARNER, P.; BERCOVIER, H. Restriction fragment length polymorphisms of $16 \mathrm{~S}$ rDNA and of wholer RNA genes (ribotyping) of Streptococcus iniae strains from the United States and Israel. FEMS Microbiology Letters, Amsterdam, v.151, n.2, p.155-162, 1997.

EVANS, J. J.; SHOEMAKER, C. A.; KLESIUS, P. H. Experimental Streptococcus iniae infection of hybrid striped bass (Morone chrysops X Morone saxatilis) and tilapia (Oreochromis niloticus) by nares inoculation. Aquaculture, Amsterdam, v.189, p.197-210, 2000

FERNANDES, M. N.; RANTIN, F. T. Relationship between oxygen availability and metabolic cost of breathing in Nile tilapia (Orechromis niloticus): aquacultural consequences. Aquaculture, Amsterdam, v.127, p.339-346, 1994.

GOLTERMAN, H. L.; CLYMO, R. S.; OHNSTAD, M. A. M. Methods for physical and chemical analysis of freshwater. London: Blackwell Sci. Publ.; 1978.

KRIEG, N. R.; HOLT, J. G. Bergey's manual of systematic bacteriology. $9^{\text {th }}$ ed. Baltimore: Williams \& Wilkins, 1984.

KITAO, T. Streptococcal infections. In: INGLIS, V.; ROBERTS, R. J.; BROMAGE, N. R. Bacterial Diseases of Fish. Oxford: Blackwell, 1993. p. 196-210.

KUBITZA, F. Tilápia: tecnologia e planejamento na produção comercial. Jundiaí: Fernando Kubitza, 2000.

KUSUDA, R.; KAWAI, K.; TOYOSHIMA, T.; KOMATSU, I. A new pathogenic bacterium belonging to the genus Streptococcus, isolated from an epizootic of cultured yellowtail. Bulletin of Marine Sciences and Fisheries, Minato, v.42,p.1345-1352, 1976.

KUSUDA, R.; KOMATSU, I. A comparative study of fish pathogenic Streptococcus isolated from saltwater and freshwater fishes. Bulletin of Marine Sciences and Fisherie, Minato, v.44, p.1073-1078, 1978.

MARTINS, M. L.; ROMERO, N. G. Efectos del parasitismo sobre el tejido branquial en peces cultivados: estudio parasitologico e histopatologico. Revista Brasileira de Zoologia, São Paulo, v.13, n.2, p.489-500, 1996.

MARTINS, M. L. Doenças infecciosas e parasitárias de peixes. 2.ed. Jaboticabal, FUNEP, 1998.
MINAMI, T. A beta-hemolitic Streptococcus isolated from cultured yellowtail. Fish Pathology, Bunkyo-Ku, v.14, p.15-19, 1979.

ORTEGA, C.; MÚSQUIZ, J. L.; DOCANDO, J.; PLANAS, E.; ALONSO,.J. L.; SIMÓN, M. C. Ecopathology in aquaculture: risk factors in infectious disease outbreak. Veterinary Research, Paris, v.26, p.57-62, 1995.

PADUA, H. B. de. Conhecimento e utilização das variáveis físicas, químicas e biológicas na aquicultura dulcícola brasileira. In. SIMPÓSIO BRASILEIRO SOBRE CULTIVO DE CAMARÃO, 4., SIMPÓSIO BRASILEIRO DE AQUICULTURA, 1., FEIRA DE TECNOLOGIA E PRODUTOS PARA AQUICULTURA, 1993, João Pessoa. Anais... João Pessoa, 1993. p.315-363.

PERERA, R. P.; JOHNSON, S. K. Streptococcus iniae associated with mortality of Tilapia nilotica $\mathrm{x}$ Tilapia aurea hybrids. Journal of Aquatic Animal Health, Bethesda, v.6, p.335-340, 1994.

PERERA,R.P.;JOHNSON,S.K.;DONALD,H.L.Epizootiological aspects of Streptococcus iniae, afecting tilapia in Texas. Aquaculture, Amsterdam, v.152, p.25-33, 1997.

PIER, G. B.; MADIN, S. H. Steptococcus inae sp. nov a beta hemolytic streptococcus isolated from a Amazon freshwater dolphin, Inia geoffrensis. International Journal of Systematics Bacteriology, Reading, v.26, p.545$553,1976$.

PLUMB, J. A. Health maintenance and principal microbial diseases of cultured fishes. Ames, Iwoa: Iwoa State University Press, 1999.

POPMA, T.; LOVSHIN, L. Aspectos relevantes da biologia e do cultivo das tilápias. Panorama da Aquicultura, Rio de Janeiro, v.5, n.27, p.8-13, 1995.

RASHEED, V.; PLUMB, J. A. P athogenicity of a nonhemolitic group B Streptococcus sp. in gulf killifish (Fundulus Grandis Baird and Girard). Aquaculture, Amsterdam, v.37, p.97-105, 1984.

ROBERTS, R. J; SOMMERVILLE, C. Disease of tilapias. In: PULLIN, S. V.; LOWE-MAC CONNEL, R. H. (Ed.). Biology and culture of tilapias. Manilla: International Center for Living Aquatic Resources Management, 1982. p.247-263.

SHOEMAKER, C. A.; EVANS, J. J.; KLESIUS, P. H. Density and dose: factors affecting mortality of Streptococcus iniae infected tilapia (Oreochomis niloticus). Aquaculture, Amsterdam, v.188, n.3-4, p.229-235, 2000.

TAVARES, L. H. S.; MORENO, S. Q. Variação dos parâmetros limnológicos em um viveiro de piscicultura nos períodos de seca e chuva. Revista UNIMAR, Maringa, v.16, n.4., p.229-242, 1994. 
TAVARES, L. H. S. Limnologia aplicada à piscicultura. Botucatu: Centro de Aquicultura da UNESP, 1995a. (Boletin Técnico, n.1)

. Influência da luz, manejo e tempo de residência sobre algumas variáveis limnológicas em um viveiro de piscicltura. Biotemas, Florianópolis, v.8, n.1, 1995b.

SURESH, A. V. Tilapia Update 1998. World Aquacult., Baton Rouge, v.30, n.4, p.8-68. 1998.

THATCHER, V. E.; BRITES NETO, J. Diagnóstico, prevenção e tratamento das enfermidades de peixes neotropicais de água doce. Revista Brasileira de Médicina Veterinária, Rio de Janeiro, v.16, n3, p111-128, 1994.

UGAJIN, M. Studies on Streptococcus sp as a causative agent of an epizootic among the cultured ayu
(Plecoglossus altivelis) in Tochigi Prefecture, Japan, 1980. Fish Pathology, Bunkyo-Ku, v.16, p.119-127, 1981.

VANDAMME, P.; DEVRIESE, L. A.; POT, B.; KERSTERS, K.; MELIN, P. Streptococcus difficile is a nonhemolytic Group B, tipe Ib Streptococcus. International Journal of Systematics Bacteriolog, Reading, v.47, n.1, p.81-85, 1997.

VAN MUISWINKEL, W. B. (Ed.). Fish Imunology. London: Academic Press, 1985. 